\title{
Pola Efikasi Guru-Guru Novis Sekolah Menengah
}

\author{
KHALID JOHARI \\ Universiti Malaysia Sabah
}

\begin{abstract}
ABSTRAK
Kajian ini bertujuan untuk menentukan aras efikasi guru dalam kalangan guru-guru novis yang mengajar di 21 buah sekolah menengah di Sabah, Malaysia. Di samping itu, perbezaan efikasi guru mengikut jantina, jenis latihan guru dan subjek pengajaran juga dikaji. Data dikumpul menggunakan "Teacher Sense of Efficacy Scale" daripada 176 guru novis di 21 buah sekolah. Dapatan menunjukkan min efikasi guru novis berada pada aras sederhana tinggi, dengan lebih memberi tumpuan terhadap pengurusan kelas. Dapatan menunjukkan efikasi guru adalah berbeza secara signifikan mengikut jantina, jenis latihan guru dan subjek pengajaran. Jenis latihan guru didapati lebih utama dalam menyumbang perbezaan ke atas efikasi guru berbanding jantina dan subjek pengajaran. Kajian ini mencadangkan agar guru-guru novis diberi ruang yang lebih luas dalam meningkatkan tahap profesionalisme guru.
\end{abstract}

\section{ABSTRACT}

Purpose - This study was aimed at determining the level of teacher efficacy among novice teachers in 21 secondary schools in Sabah, Malaysia. It also intended to investigate if there is any difference in teacher efficacy with respect to gender, types of teacher training and teaching subject.

Method - Using the causal comparison design study, data were collected using the Teacher Sense of Efficacy Scale from 176 novice teachers.

Findings - The mean obtained for teacher efficacy was moderately high, with novice teachers being more efficacious in class management. The findings showed that there were significant differences in teacher efficacy according to gender, types of teacher training, and teaching subject. The types of teacher training was found to be the main contributor to the variance in teacher efficacy as compared to gender and teaching subject. 
Value - The study might implicate the conventional practice in school systems pertaining to professionalism opportunities upon novice teachers.

Keywords - Teacher efficacy, Novice teacher, Gender, Teacher training, Subject matter.

\section{PENGENALAN}

Guru yang telah menamatkan program pendidikan guru dan baru memulakan perkhidmatannya di sekolah-sekolah dikenali sebagai guru novis. Menurut Abu Bakar (1995), guru novis merupakan guruguru sandaran terlatih yang ditempatkan di sekolah-sekolah selepas menjalani latihan perguruan dalam satu jangka masa yang ditetapkan oleh maktab-maktab perguruan atau universiti-universiti. Manakala Mohammed Sani, Zamri dan Norasmah (2006) memberi definisi guru novis sebagai guru baru yang terlatih dan mula berkhidmat di antara satu hingga tiga tahun, dalam tempoh percubaan dan belum disahkan lagi dalam jawatan.

Dalam keadaan yang masih baru dengan profesyen guru dan komuniti sekolah, mereka dikelilingi dengan persekitaran serta tanggungjawab pengajaran yang serupa dihadapi oleh guru berpengalaman; yang menuntut aplikasi pelbagai pengetahuan dan kemahiran pedagogi. Namun dapatan kajian lepas menunjukkan program latihan guru bukanlah jaminan bahawa seseorang guru telah bersedia sepenuhnya menjalankan pengajaran sebenar (Housego, 1990). Sementara kajian Marso dan Pigge (1987) mendapati guruguru biasanya menganggap kursus-kursus yang diambil semasa mengikuti pengajian pendidikan guru lebih bersifat teori dan secara praktikalnya tidak berkesan dalam melaksanakan pengajaran sebenar. Keadaan sedemikian memberi kesan negatif khususnya terhadap efikasi guru novis dalam melaksanakan pengajaran. Konsep efikasi guru adalah berkaitan dengan kepercayaan guru terhadap keupayaan diri untuk melakasanakan tugas-tugas pengajaran bagi mencapai matlamat pengajaran secara khusus (Bandura, 1997; Woolfolk-Hoy, 2000). Tschannen-Moran dan Woolfolk-Hoy (2001) mendefinisikan efikasi guru sebagai pertimbangan guru terhadap keupayaannya untuk mencapai hasil yang diharapkan dalam penglibatan dan pembelajaran murid, walaupun ada di antaranya murid yang sukar dan tidak bermotivasi. 


\section{KONSTRUK EFIKASI}

Konstruk berkaitan kepercayaan efikasi kendiri dipelopori oleh Bandura (1997) menerusi teori kognitif sosial, iaitu kepercayaan individu terhadap keupayaannya untuk menyelaras dan melaksanakan tindakan-tindakan yang diperlukan selaras dengan aras keupayaan yang dimiliki untuk mencapai hasil yang dikehendaki. Aras efikasi yang tinggi mendorong kesungguhan guru mencapai matlamat pengajaran. Manakala guru yang berefikasi rendah cenderung bersikap pasif serta menjadikan masalah dan kerisauan diri sebagai asas pertimbangan berbanding membuat perancangan yang teliti dalam tugasannya.

Menurut Bandura (1997) efikasi guru mula terbentuk sewaktu guru pelatih menjalani latihan mengajar. Pada peringkat ini, efikasi guru-guru pelatih didapati mempunyai perkaitan dengan kepercayaan mereka terhadap kawalan murid. Guru-guru pelatih yang berkepercayaan tinggi terhadap keupayaan diri dalam melaksanakan pengajaran beranggapan bahawa latihan mengajar sangat berkesan dengan memperlihatkan kepuasan kerja yang tinggi serta tahap stres yang rendah, berbanding dengan guru-guru pelatih yang berefikasi rendah.

Dapatan kajian Woolfolk-Hoy (2000) ke atas pola perkembangan efikasi guru pelatih hingga setelah berkhidmat sebagai guru mendapati bahawa kepercayaan efikasi cenderung meningkat sepanjang menjalani latihan mengajar berbanding kepercayaan efikasi yang menurun ketika berada di tahun pertama menjalankan tugas sebagai guru. Faktor peningkatan efikasi banyak dipengaruhi oleh sokongan dan bimbingan sewaktu menjalani latihan mengajar.

\section{KAJIAN-KAJIAN LEPAS}

Menerusi literatur kajian-kajian lepas mendapati faktor-faktor berkaitan guru seperti jantina, latihan guru dan subjek pengajaran merupakan antara beberapa faktor yang berpotensi mempengaruhi pola efikasi guru. Misalnya, isu berkaitan jantina biasanya dikaitkan dengan sifat, peranan dan pembawaan yang berbeza antara lelaki dan perempuan. Isu berkaitan faktor jantina berpotensi mencorakkan aras kekuatan kolektif profesionalisme guru; dan seterusnya memberi kesan ke atas pencapaian murid. Misalnya efikasi guru perempuan di sekolah menengah didapati lebih tinggi berbanding guru lelaki (Egger, 2006; Kurz, 2001). Terdapat kajian yang mendapati efikasi 
guru lelaki lebih tinggi berbanding guru perempuan (Imants \& De Brabander, 1996; Rahmah, Mohd Majid, Habibah \& Foo, 2006). Namun kajian Tschnannen Moran dan Woolfolk Hoy (2007) mendapati faktor jantina dan latihan guru tidak mempunyai perkaitan dengan efikasi guru.

Dapatan kajian Rahmah et al. (2006) menunjukkan efikasi guru novis berbeza mengikut jantina dan latihan guru. Guru lelaki dan guru siswazah lebih berefikasi berbanding guru perempuan dan guru bukan siswazah. Kajian Little (1995) pula melaporkan bahawa $44 \%$ guru mengatakan mereka tidak diberi latihan formal mengenai pengurusan kelas ketika menjalani latihan guru di Victoria. Terdapat banyak kajian lepas yang mendedahkan tanggapan guru bahawa mereka tidak dilatih dengan baik dalam mengurus masalah tingkah laku murid (Buell, Hallan, Gamel-Mc Cormich \& Scheer 1999; Cains \& Brown, 1996; Villa, Thousand \& Chapple, 1996).

Dalam aspek subjek pengajaran, kajian-kajian lepas (Capa, 2005; Wilson \& Tan, 2004) mendapati bahawa subjek pengajaran mampu memberi pengaruh yang signifikan ke atas efikasi guru novis. Dapatan kajian Capa (2005) menunjukkan subjek pengajaran merupakan penyumbang utama ke atas efikasi guru-guru yang baru mengajar pada tahun pertama berbanding faktor sokongan guru berpengalaman.

\section{TUJUAN KAJIAN}

Kajian ini dijalankan bagi menentukan aras efikasi guru-guru novis yang mengajar di sekolah menengah, di Sabah, Malaysia. Di samping itu, kajian ini juga bertujuan untuk mengenal pasti pengaruh faktorfaktor guru, iaitu jantina, jenis latihan guru dan subjek pengajaran ke atas efikasi guru-guru novis.

\section{KAEDAH KAJIAN}

Data dikumpul dengan menggunakan instrumen Teacher Sense of Efficacy Scale (TSES) yang mengandungi dua belas item yang dibina oleh Tschannen-Moran dan Woolfolk-Hoy (2001). Instrumen TSES terbahagi kepada tiga dimensi, iaitu penglibatan murid (mengukur kesungguhan guru dalam memberi dorongan kepada murid), strategi pengajaran (kesungguhan guru dalam memberi kefahaman kepada murid) dan pengurusan kelas (kesungguhan guru dalam mengawal kelas) dan menggunakan sembilan poin skala pengukuran. 
Selaras dengan keperluan kajian inia instrumen asal TSES dalam versi bahasa Inggeris diterjemahkan ke dalai bahasa Melayu; yang kemudiannya diterjemahkan semula ke dalam bahasa Inggeris oleh pakar dalam bahasa Inggeris. Perbandingan kedua-dua versi Inggeris (asal dan terjemahan semula) dilakukan dan jika terdapat perbezaan pada versi terjemahan semula, maka versi bahasa Melayu diperbaiki. Bagi menentukan aras ketekalan instrumen terjemahan, TSES versi bahasa Melayu kemudian diuji-rintis ke atas 98 orang guru di empat buah sekolah menengah dalam dua daerah di Pulau Pinang. Hasil ujian rintis tersebut mendapati ketiga-tiga dimensi berada pada aras yang tinggi, penglibatan murid $(\mathrm{a}=.80)$, strategi pengajaran $(\mathrm{a}=.76)$ dan pengurusan kelas $(\mathrm{a}=.85)$. Secara keseluruhan, aras kebolehpercayaan yang diperoleh bagi instrumen TSES (12 item) ialah alpha .92).

Soal selidik diedar kepada 350 orang guru terlatih dengan pengalaman mengajar kurang daripada tiga tahun; yang mengajar di 21 buah sekolah menengah dalam empat buah daerah di Sabah, Malaysia. Sampel dipilih menerusi persampelan bertujuan, tanpa membezakan antara sekolah bandar atau luar bandar. Ciri-ciri sampel adalah guru-guru novis sekolah menengah yang tidak terlibat dengan kelas pemulihan ataupun guru kaunseling. Sejumlah 245 set soal selidik dapat dikumpul semula namun hanya $71.8 \%$ (176 soal selidik) sahaja yang sesuai dianalisis. Guru lelaki terdiri daripada 41 orang (23.3\%) manakala guru perempuan seramai 124 (70.5\%); taburan jenis latihan guru adalah 10.8 (\%) DPLI, $17.6(\%)$ KPLI dan 68.2 (\%) B.Ed. Dari segi subjek pengajaran, seramai 20.5 peratus mengajar dalam bidang bahasa, $16.5(\%)$ sains gunaan, 25.6 (\%) sains tulen dan $37.5(\%)$ sains sosial Data dianalisis dengan menggunakan teknik ANOVA, di samping penggunaan statistik deskriptif untuk menerangkan taburan responden.

\section{DAPATAN KAJIAN}

\section{Pola Efikasi Guru Novis}

Analisis statistik deskriptif pada Jadual 1 menunjukkan taburan min efikasi guru dalam kalangan responden. Keputusan analisis menunjukkan efikasi guru novis secara keseluruhannya berada pada aras sederhana tinggi $(M=6.66, S D=1.11)$ berdasarkan skala sembilan poin yang digunakan. Efikasi guru novis lebih tertumpu kepada keupayaan mengurus kelas $(M=6.73, S D=1.26)$; diikuti dengan strategi pengajaran $(M=6.66, S D=1.18)$ dan penglibatan murid $(M=6.58, S D=1.15)$. 
Jadual 1

Pola Efikasi Guru Novis (N=176)

\begin{tabular}{lcc}
\hline & $M$ & $S D$ \\
\hline Efikasi guru & 6.66 & 1.11 \\
Penglibatan murid & 6.58 & 1.15 \\
Strategi pengajaran & 6.66 & 1.18 \\
Pengurusan kelas & 6.73 & 1.26 \\
\hline
\end{tabular}

Keputusan analisis deskriptif pada Jadual 2 menerangkan aras efikasi guru mengikut pecahan jantina, latihan guru dan subjek pengajaran. Faktor jantina dan latihan guru membentuk pola perbezaan yang konsisten, iaitu guru novis lelaki dan guru novis keluaran KPLI berada pada aras min efikasi tertinggi berbanding guru novis perempuan dan guru novis keluaran DPLI dan B.Ed dalam efikasi guru, penglibatan murid, strategi pengajaran dan pengurusan kelas. Faktor subjek pengajaran pula mendapati guru novis yang mengajar subjek sains sosial berada pada min lebih tinggi dalam efikasi guru dan penglibatan murid, berbanding guru novis yang mengajar subjek lain. Guru novis yang mengajar subjek sains gunaan berefikasi lebih tinggi dalam strategi pengajaran dan pengurusan kelas.

Jadual 2

Min Efikasi Mengikut Jantina, Latihan Guru dan Subjek Pengajaran

\begin{tabular}{|c|c|c|c|c|c|c|c|c|c|c|}
\hline & & \multicolumn{2}{|c|}{ Jantina } & \multicolumn{3}{|c|}{ Latihan Guru } & \multicolumn{4}{|c|}{ Subjek Pengajaran } \\
\hline & & $\mathrm{L}$ & $\mathrm{P}$ & KPLI & DPLI & B.Ed & BA & SG & ST & SS \\
\hline \multirow{3}{*}{ Efikasi Guru } & $N$ & 41 & 124 & 31 & 19 & 120 & 36 & 29 & 45 & 66 \\
\hline & $M$ & 6.99 & 6.52 & 7.25 & 6.97 & 6.40 & 6.76 & 6.81 & 6.24 & 6.82 \\
\hline & $S D$ & 1.01 & 1.11 & 1.04 & .88 & 1.07 & 1.01 & 1.07 & 1.29 & .98 \\
\hline \multirow{3}{*}{$\begin{array}{l}\text { Penglibatan } \\
\text { Murid }\end{array}$} & $N$ & 41 & 124 & 31 & 19 & 120 & 36 & 29 & 45 & 66 \\
\hline & $M$ & 6.89 & 6.46 & 7.08 & 6.96 & 6.33 & 6.71 & 6.62 & 6.23 & 6.74 \\
\hline & $S D$ & .94 & 1.18 & 1.12 & .97 & 1.09 & 1.10 & 1.22 & 1.35 & .95 \\
\hline \multirow{3}{*}{$\begin{array}{l}\text { Strategi } \\
\text { Pengajaran }\end{array}$} & $N$ & 41 & 124 & 31 & 19 & 120 & 36 & 29 & 45 & 66 \\
\hline & $M$ & 6.99 & 6.53 & 7.23 & 6.91 & 6.42 & 6.68 & 6.82 & 6.30 & 6.81 \\
\hline & $S D$ & 1.12 & 1.19 & 1.09 & 1.17 & 1.14 & 1.12 & 1.16 & 1.27 & 1.13 \\
\hline \multirow{3}{*}{$\begin{array}{l}\text { Pengurusan } \\
\text { Kelas }\end{array}$} & $N$ & 41 & 124 & 31 & 19 & 120 & 36 & 29 & 45 & 66 \\
\hline & $M$ & 7.09 & 6.58 & 7.42 & 7.04 & 6.45 & 6.89 & 6.99 & 6.18 & 6.91 \\
\hline & $S D$ & 1.23 & 1.24 & 1.08 & .81 & 1.29 & 1.06 & 1.12 & 1.54 & 1.12 \\
\hline
\end{tabular}




\section{Perbezaan Efikasi Guru Mengikut Jantina, Latihan Guru dan Subjek pengajaran}

Keputusan analisis ANOVA dalam Jadual 3 menerangkan sumbangan pengaruh variabel kajian ke atas efikasi guru novis. Perbezaan padaefikasigurudan dimensi-dimensinyaadalah signifikan mengikut faktor jantina dan latihan guru. Nilai sumbangan varians faktor jantina ke atas efikasi guru adalah kecil (3.4\%) penglibatan murid $(2.7 \%)$, strategi pengajaran $(2.9 \%)$ dan pengurusan kelas (3.1\%); manakala faktor latihan guru menyumbang varians yang sederhana ke atas efikasi guru (9.9\%), penglibatan murid (8.2\%), strategi pengajaran $(7.7 \%)$ dan pengurusan kelas $(9.5 \%)$. Sementara subjek pengajaran hanya menyumbang perbezaan yang signifikan pada dimensi pengurusan kelas $(F=4.126, p<.01)$ dengan nilai varians sebanyak $6.7 \%$.

Jadual 3

Perbezaan Efikasi Guru Mengikut Jantina, Latihan Guru dan Subjek pengajaran

\begin{tabular}{llcrcccc}
\hline & & Levene & SS & df & MS & F & p \\
\hline \multirow{4}{*}{ Jantina } & Efikasi guru & .260 & 6.778 & 1 & 6.778 & 5.779 & .017 \\
& Penglibatan murid & .045 & 5.712 & 1 & 5.712 & 4.519 & .035 \\
& Strategi pengajaran & .758 & 6.682 & 1 & 6.682 & 4.888 & .028 \\
& Pengurusan kelas & .559 & 8.040 & 1 & 8.040 & 5.218 & .024 \\
& & & & & & & \\
Latihan guru & Efikasi guru & .712 & 20.184 & 2 & 10.092 & 9.213 & .000 \\
& Penglibatan murid & .692 & 17.754 & 2 & 8.877 & 7.503 & .001 \\
& Strategi pengajaran & .068 & 18.015 & 2 & 9.007 & 6.992 & .001 \\
& Pengurusan kelas & .114 & 25.601 & 2 & 12.800 & 8.784 & .000 \\
Subjek & & & & & & & \\
pengajaran & Efikasi guru & .201 & 10.834 & 3 & 3.611 & 3.055 & .030 \\
& Penglibatan murid & .029 & 7.884 & 3 & 2.628 & 2.031 & .111 \\
& Strategi pengajaran & .684 & 8.151 & 3 & 2.717 & 1.987 & .118 \\
& Pengurusan kelas & .024 & 18.729 & 3 & 6.243 & 4.126 & .007 \\
\hline
\end{tabular}

Keputusan analisis post-hoc perbandingan (Tukey) dalam Jadual 4 mendapati guru novis lepasan KPLI berbeza secara signifikan dan konsisten daripada guru novis lepasan B.Ed dalam efikasi guru dan dimensi-dimensinya. Namun, guru-guru novis DPLI tidak berbeza daripada guru-guru novis keluaran program KPLI dan B.Ed. Manakala guru novis yang mengajar bidang sains tulen berbeza daripada guru novis dalam bidang sains sosial dan sains gunaan pada efikasi guru dan dimensi pengurusan kelas. 
Jadual 4

Analisis Post-Hoc Perbandingan Mengikut Latihan Guru dan Subjek Pengajaran

\begin{tabular}{|c|c|c|c|c|c|}
\hline & \multicolumn{2}{|c|}{$\begin{array}{c}\text { Latihan Guru / Subjek } \\
\text { Pengajaran }\end{array}$} & \multirow[t]{2}{*}{$(I-J)$} & \multirow[t]{2}{*}{$S E$} & \multirow[t]{2}{*}{$p$} \\
\hline & (I) & $(J)$ & & & \\
\hline Efikasi guru & \multirow{4}{*}{ KPLI } & \multirow{4}{*}{ B.Ed. } & .84393 & .21087 & .000 \\
\hline Penglibatan murid & & & .75148 & .21914 & .002 \\
\hline Strategi pengajaran & & & .81304 & .22868 & .001 \\
\hline Pengurusan kelas & & & .96727 & .24322 & .000 \\
\hline \multirow{2}{*}{ Efikasi guru } & \multirow{3}{*}{ Sains tulen } & Sains sosial & -.58552 & .21019 & .030 \\
\hline & & Sallis SUStal & -.73131 & .23781 & .013 \\
\hline Pengurusan kelas & & Sains gunaan & -.81360 & .29293 & .031 \\
\hline
\end{tabular}

\section{PERBINCANGAN DAN IMPLIKASI KAJIAN}

Dapatan kajian memberi petunjuk bahawa secara keseluruhannya, kepercayaan guru-guru novis terhadap keupayaan dalam melaksanakan pengajaran berada pada aras yang sederhana tinggi, dengan tumpuan yang lebih ke atas dimensi pengurusan kelas. Dapatan kajian ini selaras dengan dapatan Rahmah et al. (2006) dan Tschnannen-Moran dan Woolfolk-Hoy (2002). Meskipun kajian ini memperoleh aras min efikasi guru yang lebih rendah daripada dapatan Tschnannen-Moran dan Woolfolk-Hoy (2002) namun aras min efikasi guru novis di Sabah lebih tinggi berbanding dapatan Rahmah et al. (2006). Tumpuan efikasi guru novis di Sabah lebih tinggi dalam pengurusan kelas $(M=6.73, S D=1.26)$ berbanding strategi pengajaran $(M=6.74, S D=.77)$ seperti yang terdapat dalam kajian Rahmah et al. (2006).

Analisis ANOVA menunjukkan faktor jantina dan latihan guru menyumbang perbezaan yang signifikan ke atas efikasi guru dan dimensi-dimensinya. Dapatan ini selaras dengan dapatan kajian Rahmah et al. (2006). Sementara subjek pengajaran hanya berkesan mempengaruhi perbezaan pada dimensi pengurusan kelas. Namun dapatan ini berbeza daripada dapatan kajian Capa (2005) serta Wilson dan Tan (2004). Berdasarkan dapatan kajian antara ketigatiga faktor tersebut, jenis latihan guru menyumbang varians terbesar ke atas efikasi guru dan dimensi-dimensinya, diikuti dengan subjek pengajaran dan jantina. 
Guru novis lelaki mendominasi kesemua dimensi efikasi guru, khususnya dalam aspek pengurusan kelas, selaras dengan dapatan kajian-kajian lepas (Imants \& De Brabander, 1996; Rahmah et al., 2006). Corak hubungan yang sama juga berlaku pada guru novis keluaran program KPLI. Kecenderungan corak efikasi guru novis sedemikian memberi beberapa petunjuk. Antaranya ialah guru novis selaku individu yang masih baru dalam profesyen keguruan, berpendapat pengajaran yang terancang memerlukan kemahiran mengurus kelas dan disiplin secara berkesan (Watson, 2006). Tanggapan tersebut dikukuhkan lagi dengan sifat alamiah (nature) lelaki yang cenderung kepada kawalan.

Seperkara yang menarik daripada dapatan-dapatan kajian ini ialah terdapat perbezaan corak konstruk efikasi guru yang seragam dan konsisten mengikut faktor-faktor jantina dan jenis latihan guru. Sehubungan dengan aras sumbangan varians yang agak besar, iaitu sepuluh peratus oleh jenis latihan guru maka implikasi dapatan kajian ini ialah terdapatnya keperluan pendedahan dan induksi terhadap persekitaran pengajaran sebenar, semasa dan selepas tamat mengikuti latihan pendidikan guru.

Dapatan kajian ini juga memberi implikasi yang memerlukan pertimbangan serius dalam kalangan "stakeholders" yang bertanggungjawab dalam bidang pendidikan. Pihak yang terlibat dalam pengambilan calon guru perlu sekurang-kurangnya mengimbangi bilangan mengikut jantina. Aspek menambah bilangan guru lelaki dijangka dapat meningkatkan pengajaran dan pencapaian secara berkesan kerana kemampuan yang tinggi guru novis lelaki dalam aktiviti pembelajaran, melaksanakan pengajaran berkesan dan mengurus kelas.

Sehubungan itu, institusi pengajian tinggi awam yang bertanggungjawab mengendalikan latihan pendidikan guru hendaklah lebih proaktif dalam mentafsirkan keperluan pengajaran guru-guru pelatih sebelum mereka ditugaskan di sekolah-sekolah. Keperluan ini antaranya ialah mengambil langkah memperhalusi kurikulum pendidikan guru yang sedia ada bagi mempertingkat penguasaan pengetahuan pedagogi di kalangan guru pelatih. Di samping itu, pihak IPTA dicadangkan mewujudkan perkongsian strategik antara IPTA dengan sekolah bagi merangka dan melaksanakan model induksi dan bimbingan sebagai tindakan susulan kepada pengamalan pengajaran berkesan bagi guru-guru novis. Usaha ini perlu dilaksanakan bagi menjamin mutu pengajaran di sekolah agar dapat memenuhi keperluan pembelajaran murid. 


\section{RUJUKAN}

Abu Bakar Nordin. (1995). Cabaran pendidikan guru: Falsafah dan strategi dalam pembentukan guru yang unggul. Prosiding Seminar Kebangsaan. Bangi: Fakulti Pendidikan UKM Bangi.

Bandura, A. (1993). Perceived self-efficacy in cognitif development and functioning. Educational Psychologist 28(2), 117-148.

Bandura, A. (1997). Self-Efficacy: The exercise of control. New York: W.H. Freeman.

Buell, M., Hallam, R., Gamel-Mccormick, M., \& Scheer, S. (1999). A survey of general and special inservice needs concerning inclusion. International Journal of Disability, Development and Education, 46, 143-156.

Cains, R.A., \& Brown, C.R. (1996). Newly qualified teachers: A comparative analysis of the perceptions held by B.Ed. and PGCE-Trained primary teachers of their training routes. Educational Psychology, 16, 257-270.

Capa, Y. (2005). Factors influencing first-year teachers' sense of efficacy (Unpublished doctoral dissertation). Ohio State University.

Egger, K.J. (2006). An exploration of the relationships among teacher efficacy, collective teacher efficacy, and teacher demographic characteristics in conservative Christian schools (Unpublished doctoral dissertation). University Of North Texas.

Housego, B.E.J. (1990) Student teachers' feelings of preparedness to teach. Canadian Journal Of Education, 15, 37-56.

Imants, J. G. M. \& De Brabander, C. J. (1996). Teachers' and principals' sense of efficacy in elementary schools. Teaching and Teacher Education, 12(2), 179-195.

Kurz, T. B. (2001). An exploration of the relationship among teacher efficacy, collective teacher efficacy, and goal consensus. Dissertation Abstracts International: Section A. The Humanities and Social Sciences, 62(07). (UMI No. 3020068).

Little, J. W. (1995). Subject affiliation in High Schools that restructure. In L. Santee Siskin \& J. W. Little (Eds.), The subjects in question: Departmental Organization in The High School (pp. 172-200). New York: Teachers College Press. 
Marso, R.N. \& Pigge, F.L. (1987). Differences between selfperceived job expectations and job realities of beginning teachers. Journal of Teacher Education, 38(6), 53-56.

Mohammed Sani Ibrahim, Zamri Mahamod \& Norasmah Othman (2006). Dalam Norasmah Othman, Zamri Mahamod \& Mohammed Sani Ibrahim (peny.) Pengenalan kesediaan profesionalisme guru novis (pp 1-10). Cadangan Modul Latihan, Fakulti Pendidikan, UKM.

Rahmah Murshidi, Mohd Majid Konting, Habibah Elias \& Foo Say Fooi. (2006). Sense of efficacy among beginning teachers in Sarawak. Teaching Education, 17(3), 265-275.

Tschannen-Moran, M. \& Woolfolk-Hoy, A. (2001). Teacher efficacy: Capturing an elusive construct. Teaching and Teacher Education, 17, 783-805.

Tschannen-Moran, M. \& Woolfolk-Hoy, A. (2002 April). The influence of resources and support on teachers' efficacy beliefs. Paper presented at The Annual Meeting Of The American Educational Research Association, What Is The Value Of Understanding Beliefs? An Exploration Of Beliefs Related To Academic Achievement. New Orleans, LA.

Tschannen-Moran, M. \& Woolfolk-Hoy, A. (2007). The differential antecedents of self-efficacy beliefs of novice and experienced teachers. Teaching and Teacher Education, 23, 944-956.

Villa, R., Thousand, J., \& Chapple, J. (1996). Preparing teachers to support inclusion: Preservice and inservice programs. Theory into Practice, 35, 42-50.

Watson, S.B. (2006). Novice science teachers: Expectations and experiences. Journal of Science Teacher Education, 17, 279-290.

Wilson, P. \& G. C. I. Tan. (2004). Singapore teachers' personal and general efficacy for teaching primary social studies. International Research in Geographical and Environmental Education, 13(3), 209-222.

Woolfolk-Hoy, A. (2000 April). Changes in teacher efficacy during the early years of teaching. Paper presented in Qualitative and Quantitative Approaches to Examining Efficacy in Teaching and Learning. Annual Meeting of The American Educational Research Association, New Orleans, L.A. 